\title{
Resveratrol improves urinary dysfunction in rats with chronic prostatitis and suppresses the activity of the stem cell factor/c-Kit signaling pathway
}

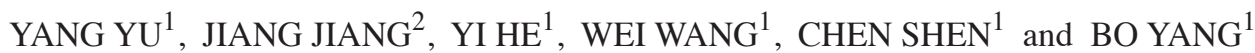 \\ ${ }^{1}$ Department of Urology, The Second Affiliated Hospital of Dalian Medical University, Dalian, Liaoning 116044; \\ ${ }^{2}$ Dalian Municipal Food and Drug Administration, Dalian, Liaoning 116000, P.R. China
}

Received April 17, 2016; Accepted March 10, 2017

DOI: $10.3892 / \mathrm{mmr} .2017 .6721$

\begin{abstract}
Chronic prostatitis (CP) is a common urological disorder, with bladder voiding dysfunction being the primary clinical manifestation. Resveratrol is polyphenolic compound isolated from numerous plants, with widely-reported anti-inflammatory properties. The present study aimed to investigate whether resveratrol may improve overactive bladder in rats with $\mathrm{CP}$ and to investigate the underlying molecular mechanisms. Furthermore, the potential pharmacological synergy between resveratrol and solifenacin was also investigated as a potential treatment for CP. Following the successful establishment of a rat model of CP by subcutaneously injecting DPT vaccine, rats were treated with resveratrol or a combination of resveratrol + solifenacin. Bladder pressure and volume tests were performed to investigate the effect of resveratrol and solifenacin on urinary dysfunction in rats with chronic prostatitis. Western blot analysis and immunohistochemical staining were used to examine the expression of c-Kit receptor, stem cell factor (SCF), AKT and phosphorylated-AKT (p-AKT) in the bladder tissue. The results of the bladder pressure and volume test indicated that the maximum capacity of the bladder, residual urine volume and maximum voiding pressure in the control group were $0.57 \mathrm{ml}, 0.17 \mathrm{ml}$ and $29.62 \mathrm{~cm} \mathrm{H}_{2} \mathrm{O}$, respectively. These values were increased by 71,27 and $206 \%$ in rats in the $\mathrm{CP}$ group compared with the control group. Following treatment with resveratrol, the results in the resveratrol group were reduced by $25.77,44.23$ and $13.32 \%$ compared with the CP group. The results of western blot analysis, immunohistochemical staining and immunofluorescence labeling demonstrate that the protein expression of SCF, c-Kit and p-AKT in the bladder of rats in the $\mathrm{CP}$ group was 4.32, 6.13 and 6.31 times higher compared
\end{abstract}

Correspondence to: $\mathrm{Dr}$ Bo Yang, Department of Urology, The Second Affiliated Hospital of Dalian Medical University, 467 Zhongshan Road, Dalian, Liaoning 116044, P.R. China E-mail: yangbo20160101@163.com

Key words: resveratrol, chronic prostatitis, urinary dysfunction, stem cell factor/c-Kit receptor, phosphatidylinositol3-kinase/AKT with the control group, respectively. Following treatment with resveratrol, protein expression was significantly reduced. However, no significant differences were observed between the protein expression of the SCF, c-Kit and p-AKT in the bladder between the resveratrol and combination groups. In conclusion, resveratrol may improve overactive bladder by downregulating the protein expression of SCF, c-Kit and p-AKT in the bladder of rats with CP. Furthermore, a combination of resveratrol and solifenacin may have potential pharmacological synergy as a treatment for patients with CP.

\section{Introduction}

Chronic prostatitis (CP) is a common urology disease and voiding dysfunction is the primary clinical manifestation (1), which is an important factor that affects the quality of life of patients with CP. It has been reported that the presence of urinary tract obstruction was revealed in patients with $\mathrm{CP}$ by urodynamic examination. Urinary tract obstruction primarily includes unstable bladder, sphincter spasm and detrusor-external sphincter dyssynergia (2).

Non-neuronal interstitial cells of Cajal (ICCs) are present in the gastrointestinal tract and are closely associated with neural stromal cells (3). Rhythmic contraction of gastrointestinal smooth muscle is regulated by ICCs (4). In addition, ICCs are associated with a variety of gastrointestinal motility disorders in pathological conditions (5). Sergeant et al (6) reported that ICC-like cells are expressed in the bladder and have an important role in the regulation of bladder activity. At present, it has been demonstrated that ICC-like cells are present in various locations in the urinary system and are morphologically and immunologically similar to ICC stromal cells $(7,8)$. These cells have important roles in the motility of smooth muscle in the urinary system, which include storage and downward transportation of urine (9). The structure and function of ICC-like cells is associated with urine carriage disorders $(10,11)$. Therefore, ICC-like cells of the urinary system are an important area of research in urodynamics.

The receptor c-Kit is also termed the stem cell factor (SCF) receptor (12), and belongs to the tyrosine kinase receptor type III family (13). It is a type of transmembrane protein tyrosine kinase in ICC-like cells $(11,14)$. c-Kit has an essential 
role in maintaining the development, normal morphology and function of ICC-like cells (15). However, the overexpression of c-Kit in the bladder has been demonstrated to cause voiding dysfunction in patients with CP (16). Therefore, reducing the expression of $\mathrm{c}-\mathrm{Kit}$ protein in ICC-like cells may effectively improve detrusor hyperactivity in patients with $\mathrm{CP}$.

Resveratrol (17) (trans-3,4,5-trihydroxy stilbene) is present in numerous plants and foods, including cassia, pine trees, grapes, wine, mulberry and peanuts. Resveratrol was originally used as a phytoalexin (18), and the extensive anti-inflammatory effects of resveratrol have been of interest to researchers (19). Furthermore, resveratrol has potent effects in reversing multidrug resistance (20). It is reported that resveratrol effectively relieves asthma by inhibiting the phosphatidylinositol3-kinase (PI3K) signaling pathway (21). The PI3K signaling pathway is a downstream pathway of c-Kit (22). Therefore, resveratrol may have the potential to improve urinary function in patients with CP. Solifenacin is currently used to improve overactive bladders in patients with CP by inhibiting muscarinic receptors (23), however, it does not effectively improve prostatitis. Due to the different targets, resveratrol and solifenacin may have potential pharmacological synergy in patients with $\mathrm{CP}$.

The present study aimed to investigate whether resveratrol may improve overactive bladder in rats with $\mathrm{CP}$ and to investigate the underlying molecular mechanisms. Furthermore, the potential pharmacological synergy of resveratrol and solifenacin is also investigated as a treatment for rats with $\mathrm{CP}$.

\section{Materials and methods}

Chemicals. Resveratrol (>99\% purity) was purchased from Dalian Meilun Biotechnology Co., Ltd. (Dalian, China). Solifenacin was purchased from Beijing Alliesyn Technology Co., Ltd. (Beijing, China). Diphtheria, pertussis and tetanus (DPT) vaccine was obtained from Wuhan Institute of Biological Products Co., Ltd. (Wuhan, China). All other chemicals used in the present study were of analytical grade and commercially available.

Animals. A total of 24 male Sprague-Dawley rats (age, 6 weeks; weight, $180 \pm 20 \mathrm{~g}$ ) were purchased from the Experimental Animal Center of Dalian Medical University (permit no. SCXK 2008-0002; Dalian, China). The rats were housed in a controlled temperature of $22 \pm 2^{\circ} \mathrm{C}$ and relative humidity of $60 \pm 5 \%$, under a $12 \mathrm{~h}$ light/dark cycle with ad libitum access to water and food; rats were fasted overnight and provided with water prior to surgery. All animal experiments were approved by the ethics committee of Dalian Medical University and performed in accordance with the institutional guidelines.

Prostatic protein isolation. Rat prostatic protein was purified from male Sprague-Dawley rats. After male Sprague-Dawley rats (weight, $200 \mathrm{~g}$ ) were sacrificed, prostate tissue was removed under sterile conditions and washed with saline solution. Prostatic tissue was subsequently placed into a physiological saline solution containing $0.5 \%$ Triton-X-100 and homogenized in an ice-water bath with a glass homogenizer. Subsequently, the homogenized liquids were centrifuged $(10,000 \mathrm{x} \mathrm{g})$ for $10 \mathrm{~min}$ at $4^{\circ} \mathrm{C}$. Proteins were quantified using a bicinchoninic acid (BCA) assay kit (Beijing Solarbio
Science \& Technology Co., Ltd., Beijing, China) and diluted to $15 \mathrm{mg} / \mathrm{ml}$ with PBS buffer (0.1 mol/l; pH 7.2).

Rat model of CP. To establish the CP model, rats were subcutaneously injected with DPT vaccine $(0.5 \mathrm{ml} / \mathrm{kg})$ on day 0 . Subsequently, they were intradermally injected at multiple points with a mixture $(1.0 \mathrm{ml})$ of purified rat prostatic protein and Freund's Complete Adjuvant (1:1) on days 0, 15 and 30 (24). The rat model of CP was completed at day 45.

Rats were randomly divided into the following four groups ( $n=6$ per group): Control group, normal rats received orally administered saline for 10 days; $\mathrm{CP}$ group, $\mathrm{CP}$ model rats received orally administered saline for 10 days; resveratrol group, CP model rats received orally administered resveratrol (10 mg/kg) (25) for 10 days; and combination group, CP model rats received orally administered resveratrol $(10 \mathrm{mg} / \mathrm{kg})$ and solifenacin $(0.7 \mathrm{mg} / \mathrm{kg})$ (26) for 10 days.

Bladder pressure and volume test in rats. Rats were anesthetized with an intraperitoneal injection of pentobarbital $(60 \mathrm{mg} / \mathrm{kg})$ prior to surgery. Subsequently, the rats were fixed on an operating frame and the upper edge of the pubic symphysis skin was cut. The bladder was exposed and placed in the incision to avoid affecting the abdominal pressure on the detrusor pressure. Two 24-gauge tubes were inserted into the bladder and fixed, and the bladder was irrigated by saline $(0.4 \mathrm{ml} / \mathrm{min})$ via one 24-gauge tube. The other tube was connected to Medlab biological signal acquisition system (Medlab $\mathrm{GmbH}$, Stutensee, Germany) via a pressure transducer. The maximum capacity of the bladder, residual urine volume and maximum voiding pressure were measured.

Morphological changes. Following bladder pressure and volume analysis, rats were sacrificed. The prostate and bladder were removed and fixed for 2 days at $25^{\circ} \mathrm{C}$ in $10 \%$ (v/v) neutral formalin and then embedded in paraffin. Tissue samples were sectioned in $4 \mu \mathrm{m}$ slices and processed by standard histological techniques. Prostatic tissue was stained with haematoxylin and eosin (H\&E) and examined for morphological changes. The protein expression of c-Kit, SCF, AKT and phosphorylated-AKT (p-AKT) was investigated in bladder tissue using western blot analysis, immunohistochemical staining and immunofluorescence labeling.

Western blot analysis. According to the manufacturer's protocol, proteins were extracted from rat bladders using a Total Protein Extraction kit (Nanjing KeyGen Biotech Co., Ltd., Nanjing, China). Protein was quantified using a BCA assay kit (Beijing Solarbio Science \& Technology Co., Ltd.), with bovine serum albumin (BSA) as the standard. Proteins $(20 \mu \mathrm{g})$ were resuspended in electrophoresis sample buffer containing $5 \% \beta$-mercaptoethanol and separated by electrophoresis on a pre-cast $10 \%$ SDS-polyacrylamide gel (Bio-Rad Laboratories, Inc., Hercules, CA, USA), followed by electrotransfer to a polyvinylidene fluoride membrane (EMD Millipore, Billerica, MA, USA). Membranes were blocked using 5\% non-fat milk in TBS with $0.1 \%$ Tween-20 (TBST) for $2 \mathrm{~h}$ at $37^{\circ} \mathrm{C}$. $\beta$-actin served as a loading control. Membranes were incubated overnight at $4^{\circ} \mathrm{C}$ with a 1:1,000 dilution of polyclonal antibodies for c-Kit (sc-168), SCF (sc-9132), AKT (sc-8312) 

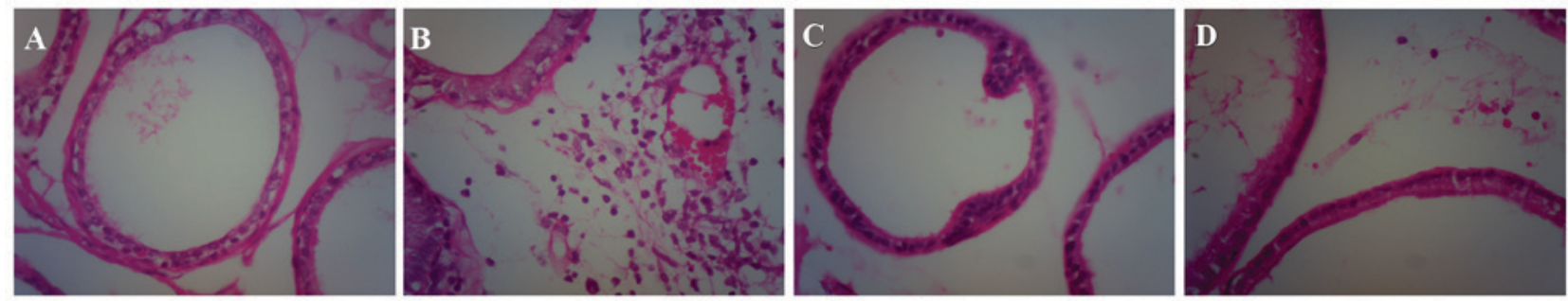

Figure 1. Prostates from (A) control (B) chronic prostatitis (C) resveratrol and (D) combination treatment groups were stained with hematoxylin and eosin. Magnification, $\mathrm{x} 400$.

and p-AKT (sc-16646-R; Santa Cruz Biotechnology, Inc., Dallas, TX, USA), and with a 1:1,500 dilution of monoclonal antibody for $\beta$-actin (bsm-33036M; BIOSS, Beijing, China). Following washing with TBST, the blots were incubated with a 1:1,000 dilution of goat anti-rabbit IgG-HRP (sc-2004; Santa Cruz Biotechnology, Inc.) for $1 \mathrm{~h}$ at $37^{\circ} \mathrm{C}$. Following extensive washing with TBST, protein bands were visualized by enhanced chemiluminescence (ECL) using ECL plus reagents from Beyotime Institute of Biotechnology according to the manufacturer's protocol. Emitted light was documented with a BioSpectrum ${ }^{\circledR}-410$ multispectral imaging system with a Chemi HR 410 camera (UVP, Inc., Upland, CA, USA). Protein bands were visualized and photographed under transmitted ultraviolet light. Blots were semi-quantified by densitometric analysis using the Image Lab software version 4.0 (Bio-Rad Laboratories, Inc.). Experiments were repeated 6 times.

Immunohistochemical staining. Histological sections of rat bladder $(4 \mu \mathrm{m})$ were mounted on poly-L-lysine-coated slides. Slides were deparaffinized in xylene and rehydrated in graded alcohols. Sections were pretreated with citrate buffer $(0.01 \mathrm{~mol} / 1$ citric acid; $\mathrm{pH} 6.0)$ for $20 \mathrm{~min}$ at $95^{\circ} \mathrm{C}$. Subsequently, at room temperature, sections were immersed in PBS containing $3 \% \mathrm{H}_{2} \mathrm{O}_{2}$ for $10 \mathrm{~min}$. Following exposure to $10 \%$ normal goat serum (ZSGB-BIO, Beijing, China) in $\mathrm{PBS}$ for $30 \mathrm{~min}$ at room temperature, the tissue sections were incubated at $4^{\circ} \mathrm{C}$ overnight with rabbit polyclonal anti-c-Kit (1:100; sc-168; Santa Cruz Biotechnology, Inc.). Sections were rinsed with PBS, incubated with biotinylated goat anti-rabbit IgG kit (SP-9001; OriGene Technologies, Inc., Beijing, China) for $20 \mathrm{~min}$ at room temperature and treated with 3,30-diaminobenzidine chromogen for $5 \mathrm{~min}$ at room temperature. Finally, sections were counterstained with hematoxylin for $6 \mathrm{~min}$ and imaged under a light microscope. A total of 6 sections and 10 randomly selected fields/section were imaged per animal.

Immunofluorescence labeling. After rinsing with PBS, rat bladder sections $(4 \mu \mathrm{m})$ were permeabilized with $0.1 \%$ Triton X-100 in PBS for 10 min and blocked with $2 \%$ BSA in PBS for $30 \mathrm{~min}$ at $37^{\circ} \mathrm{C}$. The specimen slides were incubated with primary anti-c-Kit antibody (1:100; sc-168; Santa Cruz Biotechnology, Inc.) at $4^{\circ} \mathrm{C}$ overnight. The specimens were subsequently washed three times with PBS and incubated with a cyanine 3-conjugated AffiniPure goat anti-rabbit IgG $(\mathrm{H}+\mathrm{L})$ (1:100; sa00009-4; ProteinTech Group, Inc., Chicago, IL, USA) at $37^{\circ} \mathrm{C}$ for $1 \mathrm{~h}$. Following additional washes, the immunofluorescent images were captured by $80 \mathrm{i}$ Nikon microscope
(Nikon Corporation, Tokyo, Japan). A total of 6 sections and 10 randomly selected fields/section were imaged per animal.

Statistical analysis. Statistical analysis was performed using SPSS 13.0 software (SPSS, Inc., Chicago, IL, USA). Data are presented as the mean \pm standard deviation. Statistically significant differences were compared using one-way analysis of variance followed by post hoc Tukey or Dunnett's tests for multiple comparisons. $\mathrm{P}<0.05$ was considered to indicate a statistically significant difference.

\section{Results}

Assessment of $C P$. Histological examination of H\&E-stained sections was performed to determine the extent of $\mathrm{CP}$. $\mathrm{H} \& \mathrm{E}$-stained prostate from the $\mathrm{CP}$ group demonstrated that the prostate tissues were infiltrated by a large number of inflammatory cells (Fig. 1), which indicates that the rat model of $\mathrm{CP}$ was established successfully (27).

Resveratrol improves overactive bladder in rats with $C P$. The results of the bladder pressure and volume analysis demonstrate that the maximum capacity of the bladder, residual urine volume and maximum voiding pressure in the rats of control group were $0.57 \mathrm{ml}, 0.17 \mathrm{ml}$ and $29.62 \mathrm{~cm} \mathrm{H}_{2} \mathrm{O}$, respectively (Table I). The maximum capacity of the bladder, residual urine volume and maximum voiding pressure in the rats of CP group increased by $0.71,2.06$ and 0.27 fold, respectively, compared with the control group (Table I). These results also indicate that the model of CP rats was successfully established. Following treatment with resveratrol in $\mathrm{CP}$ rats, the maximum capacity of the bladder, residual urine volume and maximum voiding pressure in the rats of resveratrol group was reduced by $25.77,44.23$ and $13.32 \%$, respectively, compared with the CP group (Table I), which indicates that resveratrol may effectively improve overactive bladder in rats with $\mathrm{CP}$ and, as the reduction observed with combination treatment was larger, pharmacological synergy of resveratrol and solifenacin may improve overactive bladder.

Resveratrol downregulates the protein expression of SCF and $c$-Kit. The results of western blot analysis demonstrate that the protein expression of SCF and c-Kit in the bladder of rats in the $\mathrm{CP}$ group was 4.32 and 6.13 times higher than in the control group (Fig. 2), respectively. However, following treatment with resveratrol, the protein expression of SCF and $\mathrm{c}-\mathrm{Kit}$ in the rat bladders was significantly reduced compared with the CP group (Fig. 2). However, no significant 
Table I. Resveratrol improves overactive bladder in rats with CP.

\begin{tabular}{lccc}
\hline Group & $\begin{array}{c}\text { Maximum } \\
\text { capacity }(\mathrm{ml})\end{array}$ & $\begin{array}{c}\text { Maximum voiding } \\
\text { pressure }\left(\mathrm{cmH}_{2} \mathrm{O}\right)\end{array}$ & $\begin{array}{c}\text { Residual urine } \\
\text { volume }(\mathrm{ml})\end{array}$ \\
\hline Control & $0.57 \pm 0.09$ & $27.62 \pm 2.98$ & $0.17 \pm 0.11$ \\
CP & $0.97 \pm 0.12^{\mathrm{a}}$ & $35.21 \pm 0.89^{\mathrm{a}}$ & $0.52 \pm 0.17^{\mathrm{a}}$ \\
Resveratrol & $0.72 \pm 0.03^{\mathrm{b}}$ & $30.51 \pm 1.14^{\mathrm{b}}$ & $0.29 \pm 0.02^{\mathrm{b}}$ \\
Combination & $0.60 \pm 0.08^{\mathrm{c}}$ & $28.78 \pm 1.03^{\mathrm{c}}$ & $0.23 \pm 0.16^{\mathrm{c}}$ \\
\hline
\end{tabular}

${ }^{\mathrm{a}} \mathrm{P}<0.01$ vs. control, ${ }^{\mathrm{b}} \mathrm{P}<0.01$ vs. $\mathrm{CP}$ and ${ }^{\mathrm{c}} \mathrm{P}<0.05$ vs. resveratrol group. $\mathrm{CP}$, chronic prostatitis.
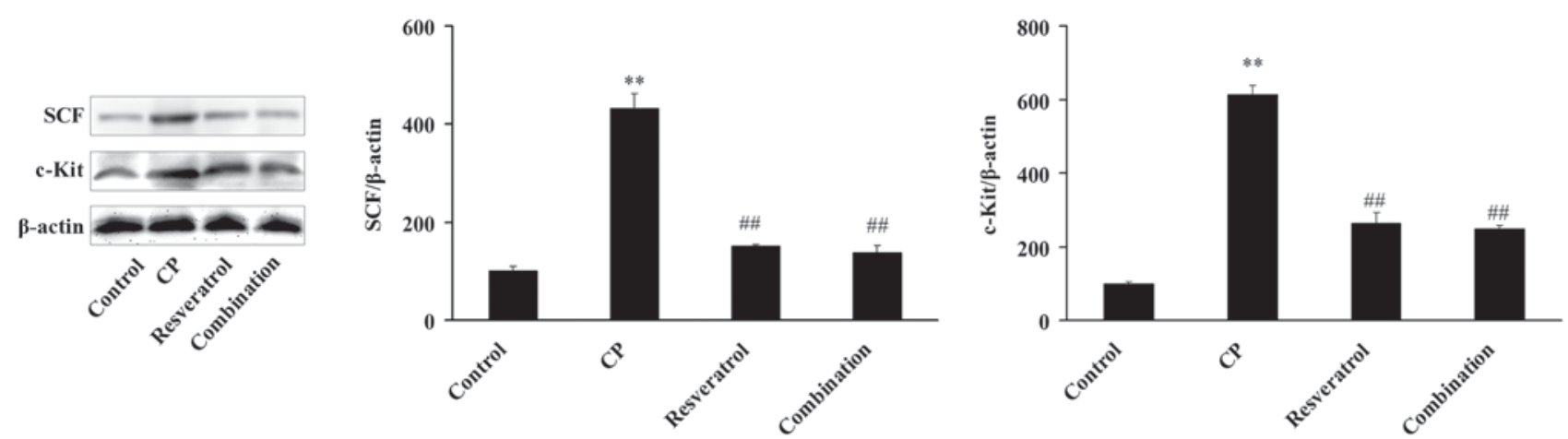

Figure 2. Effect of resveratrol on the protein expression of SCF and c-Kit in the bladders of rats with CP by western blot analysis. Relative expression ratios following normalization by $\beta$-actin are presented. Data are presented as the mean \pm standard deviation. ${ }^{* *} \mathrm{P}<0.01 \mathrm{vs}$. control and ${ }^{\# \#} \mathrm{P}<0.01 \mathrm{vs}$. $\mathrm{CP}$ ( $\mathrm{n}=6$ ). $\mathrm{SCF}$, stem cell factor; $\mathrm{CP}$, chronic prostatitis.

differences in the protein expression of SCF and c-Kit were observed between resveratrol and combination groups (Fig. 2). Immunohistochemistry and immunofluorescence results were consistent with western blot analysis results. The protein expression of c-Kit in the bladder tissue of the CP group was significantly increased compared with the control group (Figs. 3 and 4). However, following treatment with resveratrol or resveratrol + solifenacin, the protein expression of c-Kit in the bladder tissue was reduced compared with the CP group (Figs. 3 and 4), with no differences observed between resveratrol and combination groups.

Resveratrol inhibits PI3K/AKT pathway activity. The $\mathrm{PI} 3 \mathrm{~K} / \mathrm{AKT}$ pathway is a downstream signaling pathway of $\mathrm{SCF} / \mathrm{c}-\mathrm{Kit}$, therefore, the present study investigated the pathway activity of PI3K/AKT. The level of $\mathrm{p}-\mathrm{AKT}$ in the $\mathrm{CP}$ group was 6.31 times higher than in the control group (Fig. 5). However, following treatment with resveratrol or resveratrol + solifenacin, p-AKT levels were significantly reduced compared with the $\mathrm{CP}$ group (Fig. 5). The results indicate that resveratrol may suppress the activity of the PI3K/AKT signaling pathway in rats with $\mathrm{CP}$.

\section{Discussion}

The c-Kit protein was first discovered in 1987, and the human c-Kit gene is located at 4q11-12 and encodes a c-Kit protein that is a transmembrane glycoprotein of receptor tyrosine kinases class III (28). The c-Kit receptor is widely distributed on the surface of hematopoietic stem cells, myeloid progenitor cells, dendritic cells, mast cells, lymphocyte precursors, melanocytes and germ cells. In the bladder, c-Kit is primarily expressed in ICC-like cells, thus, the protein expression level of c-Kit is an indicator of the number of ICC-like cells (28). ICC-like cells, detrusor smooth muscle cells and nerves interact with each other in the bladder $(29,30)$. The ICC-like cell is closely associated with nerve signal transduction from the epithelium to smooth muscle, and the structural relationships contribute to triggering the detrusor contraction (31).

The survival, proliferation and differentiation of cells are closely associated with the activation of SCF/c-Kit signaling pathway (32-34). SCF is a c-Kit ligand and cytokine. It is considered important for c-Kit activation, survival and the function of ICCs (15). However, the excessive activation of SCF/c-Kit signaling pathway may cause abnormal proliferation of ICC-like cells in the bladder, therefore potentially causing urinary dysfunction. Therefore, the present study investigated whether the abnormal proliferation of ICC-like cells is one of the causes of voiding dysfunction in rats with $\mathrm{CP}$.

A rat model of $\mathrm{CP}$ was established by immunological methods. After the model established, changes in rat prostate morphology was investigated by H\&E staining. The results indicate that the prostate tissues of rats with CP were infiltrated by a large number of inflammatory cells. Subsequently, bladder pressure and volume tests were performed in rats. The results demonstrated that the maximum capacity of the bladder, residual urine volume and maximum voiding pressure of the rats in the $\mathrm{CP}$ group were significantly increased compared with the control group. These results also indicate that the rat model of CP was established successfully. However, after the rats were administered resveratrol, the maximum capacity of 

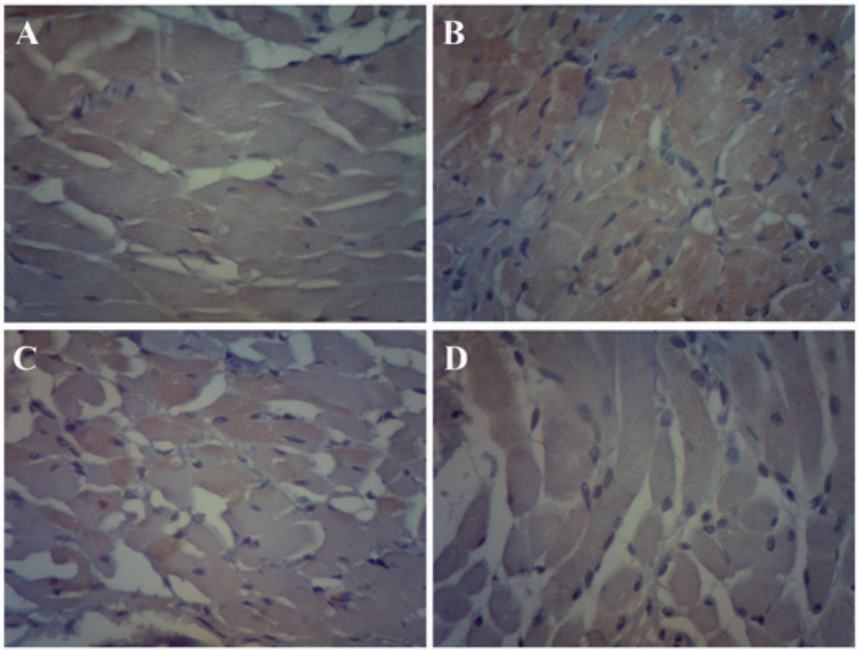

Figure 3. Effect of resveratrol on the protein expression of c-Kit in the bladder of rats with $\mathrm{CP}$. Immunohistochemical staining was performed on bladder tissue from (A) control, (B) CP, (C) resveratrol and (D) combination treatment groups. Magnification, $\mathrm{x} 400 \mathrm{CP}$, chronic prostatitis.
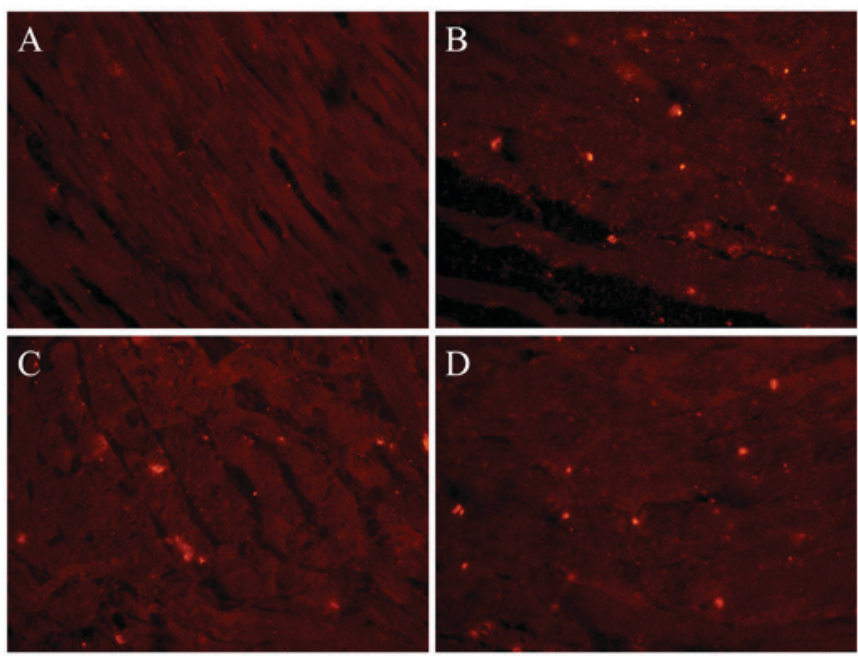

Figure 4. Effect of resveratrol on the protein expression of c-Kit in the bladder of rats with CP. Immunofluorescence labeling was performed on bladder tissue from (A) control, (B) CP, (C) resveratrol and (D) combination treatment groups. Magnification, $\mathrm{x} 400 . \mathrm{CP}$, chronic prostatitis.

the bladder, residual urine volume and maximum voiding pressure of the rats in resveratrol group were significantly reduced compared with the CP group and were further reduced with combination treatment. The results indicate that resveratrol may improve overactive bladder in rats with $\mathrm{CP}$, and pharmacological synergy between resveratrol and solifenacin was observed to improve overactive bladder.

To investigate the mechanism by which resveratrol improves overactive bladder in $\mathrm{CP}$ rats, the protein expression of SCF and c-Kit in bladder of rats was examined by western blot analysis and immunohistochemical staining. The results of western blot analysis, immunohistochemical staining and immunofluorescence labeling demonstrate that the protein expression of $\mathrm{c}-\mathrm{Kit}$ in bladders from the $\mathrm{CP}$ group were significantly increased compared with the control group. However, following treatment with resveratrol, the protein expression of c-Kit was reduced compare with the $\mathrm{CP}$ group. In addition, the

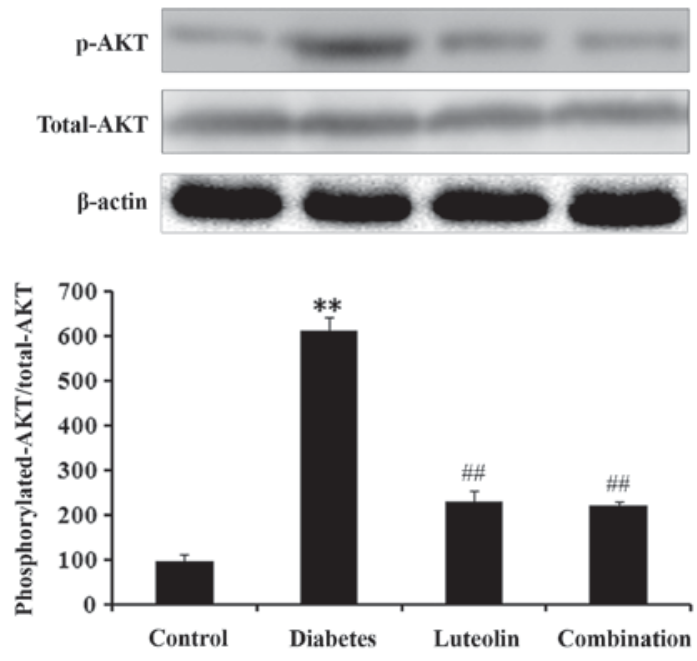

Figure 5. Resveratrol inhibits phosphatidylinositol3-kinase/AKT pathway activity in the bladder of rats with CP. Relative expression ratios of $\mathrm{p}$-AKT normalized to total AKT are presented. Data are presented as the mean \pm standard deviation. ${ }^{* *} \mathrm{P}<0.01$ vs. control and ${ }^{\# \#} \mathrm{P}<0.01$ vs. $\mathrm{CP}(\mathrm{n}=6)$ $\mathrm{CP}$, chronic prostatitis; p-AKT, phosphorylated-AKT.

results of western blot analysis demonstrated that SCF protein expression changes are similar to c-Kit. Therefore, we hypothesize that resveratrol may reduce the expression of c-Kit by downregulating SCF expression, which improves overactive bladder in rats with $\mathrm{CP}$.

Various downstream signaling pathways of $\mathrm{SCF} / \mathrm{c}-\mathrm{Kit}$ are activated when SCF specifically binds with c-Kit and forms a homodimer, including PI3K (22), Ras/Erk phospholipase $\mathrm{C}-\gamma$ and JAK/STAT signaling pathways (35). Phosphorylation of AKT is an important process in PI3K signal transduction. Therefore, the present study examined the levels of p-AKT by western blot analysis. p-AKT levels in the CP group were significantly higher compared with the control group. However, following treatment with resveratrol, p-AKT levels were significantly reduced compared with the $\mathrm{CP}$ group. The results indicate that resveratrol may suppress PI3K/AKT pathway activity, and that resveratrol may improve overactive bladder in rats with $\mathrm{CP}$ by downregulating the expression of c-Kit.

Traditional medicines have been associated with therapeutic efficacy and reduced side effects in numerous diseases. Currently, the separation, extraction and investigation of the pharmacological activity of monomer components of traditional medicines are increasingly performed in studies. Furthermore, the combination of traditional medicine and chemical drugs has emerged as a novel research direction. Solifenacin is a selective antagonist of muscarinic acetylcholine M3 receptors. It is used in the treatment of overactive bladder, which includes urgency, frequency and urge incontinence. Therefore, the present study investigated whether there is potential pharmacological synergy between resveratrol and solifenacin in the treatment of rats with $\mathrm{CP}$. The results of bladder pressure and volume tests indicated that the combination of resveratrol and solifenacin strengthened the improvement in overactive bladder. However, no differences in the protein expression of SCF, c-Kit and p-AKT were observed between resveratrol and combination groups by western blot analysis, immunohistochemical 
staining and immunofluorescence labeling. The results indicate that resveratrol and solifenacin may act on different targets to exhibit pharmacological synergy in the treatment of CP.

In conclusion, resveratrol may improve overactive bladder by downregulating the expression of SCF, c-Kit and p-AKT in the bladder of rats with CP. Furthermore, resveratrol and solifenacin may exhibit pharmacological synergy in the treatment of $\mathrm{CP}$ in rats.

\section{Acknowledgements}

The present study was conducted with the technical support of the Second Affiliated Hospital of Dalian Medical University (Dalian, China).

\section{References}

1. Cho DS, Choi JB, Kim YS, Joo KJ, Kim SH, Kim JC and Kim HW: Heart rate variability in assessment of autonomic dysfunction in patients with chronic prostatitis/chronic pelvic pain syndrome. Urology 78: 1369-1372, 2011.

2. Liao LM, Shi BY and Liang CQ: Ambulatory urodynamic monitoring of external urethral sphincter behavior in chronic prostatitis patients. Asian J Androl 1: 215-217, 1999.

3. Wei J, Li N, Xia X, Chen X, Peng F, Besner GE and Feng J: Effects of lipopolysaccharide-induced inflammation on the interstitial cells of Cajal. Cell Tissue Res 356: 29-37, 2014.

4. Shin DH, Lee MJ, Jiao HY, Choi S, Kim MW, Park CG, Na J, Kim SW, Park IK, So I and Jun JY: Regulatory roles of endogenous mitogen-activated protein kinases and tyrosine kinases in the pacemaker activity of colonic interstitial cells of cajal. Pharmacology 96: 16-24, 2015.

5. Li J, Kong D, He Y, Wang X, Gao L, Li J, Yan M, Liu D, Wang Y, Zhang $L$ and Jin $X$ : The impact of inflammatory cells in malignant ascites on small intestinal ICCs' morphology and function. J Cell Mol Med 19: 2118-2127, 2015.

6. Sergeant GP, Hollywood MA, McCloskey KD, Thornbury KD and McHale NG: Specialised pacemaking cells in the rabbit urethra. J Physiol 526: 359-366, 2000.

7. Faussone-Pellegrini MS, Serni S and Carini M: Distribution of ICC and motor response characteristics in urinary bladders reconstructed from human ileum. Am J Physiol 273: G147-G157, 1997.

8. Shafik A, El Sibai O and Ahmed I: The identification of specialized pacemaking cells in the anal sphincters. Int J Colorectal Dis 21: 453-457, 2006.

9. Thornbury KD, Hollywood MA, McHale NG and Sergeant GP: Cajal beyond the gut: Interstitial cells in the urinary system-towards general regulatory mechanisms of smooth muscle contractility? Acta Gastroenterol Belg 74: 536-542, 2011.

10. Hashitani $\mathrm{H}$ and Lang RJ: Functions of ICC-like cells in the urinary tract and male genital organs. J Cell Mol Med 14: 1199-1211, 2010.

11. Lang RJ and Klemm MF: Interstitial cell of Cajal-like cells in the upper urinary tract. J Cell Mol Med 9: 543-556, 2005.

12. Lennartsson J and Rönnstrand L: Stem cell factor receptor/c-Kit: From basic science to clinical implications. Physiol Rev 92: 1619-1649, 2012

13. Abu-Duhier FM, Goodeve AC, Care RS, Gari M, Wilson GA, Peake IR and Reilly JT: Mutational analysis of class III receptor tyrosine kinases (C-KIT, C-FMS, FLT3) in idiopathic myelofibrosis. Br J Haematol 120: 464-470, 2003.

14. Biers SM, Reynard JM, Doore T and Brading AF: The functional effects of a c-kit tyrosine inhibitor on guinea-pig and human detrusor. BJU Int 97: 612-616, 2006.

15. Roskoski R Jr: Structure and regulation of Kit protein-tyrosine kinase-the stem cell factor receptor. Biochem Biophys Res Commun 338: 1307-1315, 2005.
16. Haki Yuksel O, Urkmez A and Verit A: The role of Cajal cells in chronic prostatitis. Arch Ital UrolAndrol 88: 133-135, 2016.

17. Torres P, Poveda A, Jimenez-Barbero J, Ballesteros A and Plou FJ: Regioselective lipase-catalyzed synthesis of 3-o-acyl derivatives of resveratrol and study of their antioxidant properties. J Agric Food Chem 58: 807-813, 2010.

18. Sharma S, Anjaneyulu M, Kulkarni SK and Chopra K: Resveratrol, a polyphenolic phytoalexin, attenuates diabetic nephropathy in rats. Pharmacology 76: 69-75, 2006.

19. Csiszar A: Anti-inflammatory effects of resveratrol: Possible role in prevention of age-related cardiovascular disease. Ann N Y Acad Sci 1215: 117-122, 2011.

20. Huang F, Wu XN, Chen J, Wang WX and Lu ZF: Resveratrol reverses multidrug resistance in human breast cancer doxorubicin-resistant cells. Exp Ther Med 7: 1611-1616, 2014.

21. Poolman TM, Ng LL, Farmer PB and Manson MM: Inhibition of the respiratory burst by resveratrol in human monocytes: Correlation with inhibition of PI3K signaling. Free Radic Biol Med 39: 118-132, 2005.

22. Vajravelu BN, Hong KU, Al-Maqtari T, Cao P, Keith MC, Wysoczynski M, Zhao J, Moore JB IV and Bolli R: C-Kit promotes growth and migration of human cardiac progenitor cells via the PI3K-AKT and MEK-ERK pathways. PloS One 10: e0140798, 2015.

23. Lee SH, Byun SS, Lee SJ, Kim KH and Lee JY: Effects of initial combined tamsulosin and solifenacin therapy for overactive bladder and bladder outlet obstruction secondary to benign prostatic hyperplasia: A prospective, randomized, multicenter study. Int Urol Nephrol 46: 523-529, 2014.

24. Guohong S, Qiumei Z, Baozhen P, Lijuan H, Julaiti S, Aisikeer T, Xuan G, Lina Y, Reyihan W, Wentao Z and Qingyang P: Effects of different Chinese herbal prescriptions on cytokines in autoimmune prostatitis rats. J Tradit Chin Med 35: 211-217, 2015.

25. Cheng PW, Ho WY, Su YT, Lu PJ, Chen BZ, Cheng WH, Lu WH, Sun GC, Yeh TC, Hsiao M and Tseng CJ: Resveratrol decreases fructose-induced oxidative stress, mediated by NADPH oxidase via an AMPK-dependent mechanism. Br J Pharmacol 171: 2739-2750, 2014.

26. Suzuki M, Ohtake A, Yoshino T, Yuyama H, Hayashi A, Ukai M, Okutsu H, Noguchi Y, Sato S and Sasamata M: Effects of solifenacin succinate (YM905) on detrusor overactivity in conscious cerebral infarcted rats. Eur J Pharmacol 512: 61-66, 2005.

27. Yang X, Yuan L, Chen J, Xiong C and Ruan J: Multitargeted protective effect of Abacopteris penangiana against carrageenan-induced chronic prostatitis in rats. J Ethnopharmacol 151: 343-351, 2014.

28. Rivera RS, Nagatsuka H, Gunduz M, Cengiz B, Gunduz E, Siar CH, Tsujigiwa H, Tamamura R, Han KN and Nagai N: C-kit protein expression correlated with activating mutations in KIT gene in oral mucosal melanoma. Virchows Arch 452: 27-32, 2008.

29. Metzger R, Schuster T, Till H, Franke FE and Dietz HG: Cajal-like cells in the upper urinary tract: Comparative study in various species. Pediatr Surg Int 21: 169-174, 2005.

30. Johnston L, Woolsey S, Cunningham RM, O'Kane H, Duggan B, Keane P and McCloskey KD: Morphological expression of KIT positive interstitial cells of Cajal in human bladder. J Urol 184: 370-377, 2010.

31. McCloskey KD: Interstitial cells in the urinary bladder-localization and function. Neurourol Urodyn 29: 82-87, 2010.

32. Bashamboo A, Taylor AH, Samuel K, Panthier JJ, Whetton AD and Forrester LM: The survival of differentiating embryonic stem cells is dependent on the SCF-KIT pathway. J Cell Sci 119: 3039-3046, 2006.

33. Fraser L, Taylor AH and Forrester LM: SCF/KIT inhibition has a cumulative but reversible effect on the self-renewal of embryonic stem cells and on the survival of differentiating cells. Cell Reprogram 15: 259-268, 2013.

34. Lorincz A, Redelman D, Horvath VJ, Bardsley MR, Chen H and Ordog T: Progenitors of interstitial cells of cajal in the postnatal murine stomach. Gastroenterology 134: 1083-1093, 2008.

35. Taylor ML and Metcalfe DD: Kit signal transduction. Hematol Oncol Clin North Am 14: 517-535, 2000. 